\title{
Morphological, Viscoelastic and Mechanical Characterization of Polypropylene/Exfoliated Graphite Nanocomposites
}

\author{
Creusa lara Ferreira \\ PGCIMAT - IQ, Universidade Federal do Rio Grande do Sul, UFRGS
}

Otavio Bianchi

PGMAT - CCET, Universidade de Caxias do SUI, UCS

\section{Mauro Alfredo Soto Oviedo \\ Braskem S/A}

\author{
Ricardo Vinicius Bof de Oliveira, Raquel Santos Mauler \\ PGCIMAT - IQ, Universidade Federal do Rio Grande do Sul, UFRGS
}

\begin{abstract}
The viscoelastic, mechanical and morphological properties of polypropylene/exfoliated graphite nanocomposites with different contents of nanofiller were investigated. According to transmission electron microscopy results, the nanofiller particles were homogeneously dispersed in the matrix. The rheological properties indicated that incorporation of graphite improved the matrix stiffness and had a reinforcing effect. Exfoliated graphite had a weak interaction with the polypropylene. The behavior of the nanocomposites was similar to that of polypropylene in terms of the interfacial detachment inferred from the transmission electron microscopy images and of their G' (storage) and G" (loss) moduli, and viscosity. The mechanical properties of the nanocomposites compared to the matrix improved significantly for the flexural and storage moduli with little loss of impact strength.
\end{abstract}

Keywords: Exfoliated graphite, mechanical properties, nanocomposite, viscoelastic properties.

\section{Introduction}

Graphene has attracted a great amount of attention because of its exceptional properties, such as high tensile modulus and electrical conductivity. Graphene shows promise in nanocomposites for a wide range of applications. It can be used to improve the thermal, mechanical and electrical properties of materials and to enhance their gas barrier and thermal stability characteristics $^{[1-4]}$.

Naturally occurring graphite is the most accessible source for large quantities of graphene. In graphite, layers of graphene are maintained in stacks by van der Waals forces. Numerous studies have addressed the challenges of separating graphene layers with various methods such as oxidation-reduction, mechanical exfoliation and oxidation-thermal exfoliation. The most common approaches, Hummers's and Staudenmaier's methods, are based on treating graphite with strong oxidizer followed by thermal expansion. These approaches produce graphene in the form of monolayers and stacks with few layers. Structural polar groups from the oxidation process remain in the graphene ${ }^{[5-7]}$. These groups increase the polarity of the graphene and make it challenging to disperse the nanocomposite in apolar matrixes such as polyolefins ${ }^{[8,9]}$.

Rheology studies are used to predict nanocomposite behavior during melt compounding processes. The viscoelastic behavior of nanocomposites contributes to the understanding of their internal microstructure, such as their morphologies and nanofiller/matrix interactions ${ }^{[10-13]}$.

In this paper, the rheological properties of exfoliated graphite nanocomposites with different contents of nanofiller were analyzed. Observations of viscoelastic and mechanical behavior were related to the nanocomposite morphology to evaluate the graphite/ polypropylene interactions.

\section{Experimental Methods}

\section{Materials}

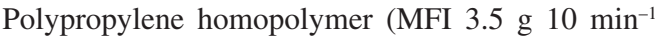
$\left(230{ }^{\circ} \mathrm{C} / 2.16 \mathrm{~kg}\right.$ ) and density $\left.0.905 \mathrm{~g} \mathrm{~cm}^{-3}\right)$ was supplied by Braskem S/A, Brazil. Exfoliated graphite Micrograf HC-11 from Nacional do Grafite (Brazil) with median particle size of $10 \mu \mathrm{m}$ (supplier data) was obtained via the well-known process of acid intercalation and posterior thermal expansion (EG-exfoliated graphite) ${ }^{[14]}$. All of the materials were used as received.

\section{Melt processing}

Polypropylene and EG were stirred in a mixer for 10 minutes at room temperature until homogenization

Corresponding author: Raquel Santos Mauler, Instituto de Química. Departamento de Química Orgânica, Universidade Federal do Rio Grande do Sul - UFRGS, Av. Bento Gonçalves, 9500, CEP 91501-970, Porto Alegre, RS, Brasil, e-mail: raquel.mauler@ufrgs.br 
was complete for $2,4,6,8$ and $10 \mathrm{wt} \%$ exfoliated graphite. In this study, all nanocomposites were melt compounded in a co-rotating twin-screw intermeshing extruder (Haake Rheomex PTW 16/25) with a $16 \mathrm{~mm}$ diameter and an L/D 25. The screw speed was $80 \mathrm{rpm}$ and the temperature profile ranged from 170 to $190{ }^{\circ} \mathrm{C}$ (from feeder to die). The samples were named PP/EG- $x$, where $x$ is the exfoliated graphite content.

\section{Characterization}

Sample morphologies were examined by transmission electron microscopy (TEM) with a JEOL JEM - 1200 Ex II, which operated at an acceleration voltage of $80 \mathrm{kV}$. Ultra-thin sections $(70 \mathrm{~nm})$ were prepared with a Leica Ultracut UCT ultramicrotome with a diamond knife at $-80{ }^{\circ} \mathrm{C}$ and collected on 300 mesh cooper TEM grids. Nanocomposite fracture and the graphite particles were evaluated by SEM (scanning electron microscopy) in a JEOL JSM - 6060 microscope, which operated at an acceleration voltage of $10 \mathrm{kV}$. Samples from the central cores of the injection-molded bars were cryo-fractured in a manner that was perpendicular to the direction in which the mold was filled. The upper surfaces of cryo-fractured samples were sputter-coated with carbon before SEM imaging.

Dynamical mechanical analyses (DMA) were performed with a TA Instruments Q800 in a multifrequency mode. The samples were analyzed in a single cantilever mode with rectangular geometry $\left(17 \times 13 \times 3.5 \mathrm{~mm}^{3}\right)$ at a frequency of $1 \mathrm{~Hz}$ and a small amplitude $(0.1 \%)$. The analyses were carried out from $-30{ }^{\circ} \mathrm{C}$ to $130{ }^{\circ} \mathrm{C}$ at a heating rate of $3{ }^{\circ} \mathrm{C} \mathrm{min}^{-1}$.

The viscoelastic behavior of the melts was analyzed with a dynamic oscillatory rheometer (an Anton Parr MCR 501 rheometer with $25 \mathrm{~mm}$ parallel plate geometry) at $200{ }^{\circ} \mathrm{C}$ under nitrogen atmosphere. The gap between the plates was set at $1 \mathrm{~mm}$. The linear viscoelastic region was determined from an amplitude sweep experiment. The frequency sweep experiments (0.06-628 rad/s) were performed using stress control (50 Pa), which was determined in the amplitude sweep experiment.

A three-point flexural test was performed at room temperature with an Instron 4466 universal testing machine according to ASTM D 790. The notched Izod impact strength was measured with a pendulum-type tester (Resil-ImpactorCeast 6545) at $23{ }^{\circ} \mathrm{C}$ according to ASTM 256. These samples were prepared in a BattenfeldPlus $350 / 75$ injection-molding machine according to ASTM D 4101 .

\section{Results and Discussion}

\section{Microstructure of PP/EG nanocomposites}

Exfoliated graphite is derived from natural graphite by chemical modification and thermal treatment. Figure 1 shows the SEM image of exfoliated graphite flaked with aggregated lamellae and a disordered structure due to the thermal shock suffered in the expansion process.

The dispersion and microstructure of the PP/EG-2 and PP/EG-10 nanocomposites were revealed in TEM images, as shown in Figure 2. The nanofiller particles were dispersed homogeneously in the matrix with small agglomerates consisting of multilayer stacks of graphene and a few graphene layers separated from the tactoids. The morphology was similar for both nanofiller rates, but the tactoids were slightly larger at the higher level of EG. It is difficult to disperse these nanoparticles in apolar matrixes, such as polypropylene, that have weak affinity for the nanofiller due to the polar groups created by the expansion process ${ }^{[15]}$.

Graphene is flexible; folded and rolled layers of graphene are present in the TEM images. The in-plane graphene is thermodynamically unstable, and this effect is shown in this work where the affinity between the matrix and the graphene is not favorable. The folded and rolled layers of graphene indicate that there is low affinity between graphene and polypropylene. The graphene did not adopt a crumpled conformation that could have suggested a weak interaction between the components ${ }^{[16,17]}$.

On the other hand, isolated graphene layers were observed. This behavior can suggest that shearing during extrusion was able to disrupt graphite tactoids structure due to the low-energy interactions (weak van der Waals forces) between graphene lamellae.

\section{Viscoelastic properties of PP/EG nanocomposites}

Solid-state analysis with DMA measures the storage $\left(E^{\prime}\right)$ and loss (E’) moduli (Figure 3). All samples showed pseudo solid-elastic behavior throughout the entire temperature range in this work. In the PP matrix, the EG increased the values of $E$ ' and $E$ "' over the entire temperature range because it restricted the amplitude of the molecular vibrations. This increase in the moduli indicates that the exfoliated graphite improves the stiffness of the matrix and has a reinforcing effect. However, the addition of larger amounts of EG into PP also results in the formation of clusters (see TEM images), which dissipate energy and increase the solid viscous component $(E$ ") .

Figure 4 shows the damping or loss factor $(\tan \delta$ ) that is related to the ratio of the loss and storage moduli $\left(E^{\prime \prime} / E^{\prime}\right)$. The range between -10 and $30{ }^{\circ} \mathrm{C}(\beta$-transition)

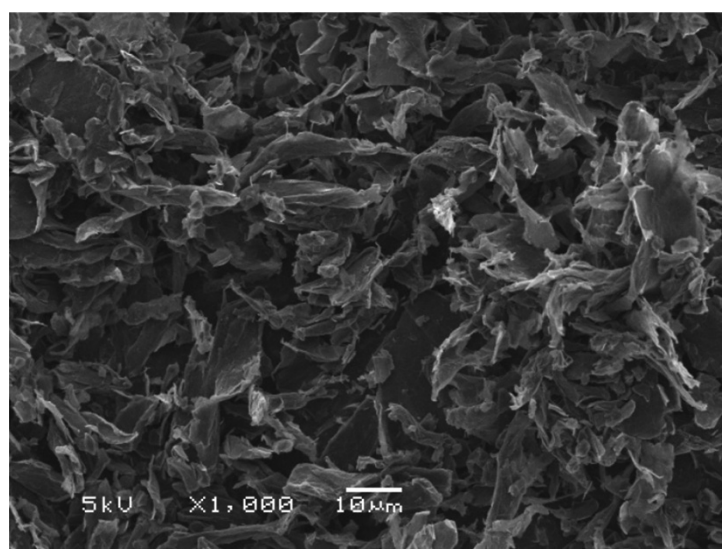

Figure 1. SEM micrograph of the exfoliated graphite. 
corresponds to the glass-rubber transition (Tg) of PP. The transition between 60 and $120^{\circ} \mathrm{C}$ can be related to the movement of intracrystalline amorphous segments $(\alpha \text {-relaxation })^{[18,19]}$

In addition, Figure 4 demonstrates a reduction of the intensity and a small dislocation of the $\beta$ transition to higher temperatures (approximately $3{ }^{\circ} \mathrm{C}$ ) with the EG addiction relative to neat polypropylene.The intensity decrease effect could be associated with the reduction of the motion of the amorphous segments due hindrance by the graphite, or in other words, an increase in the elastic component of the material. Moreover, graphite slightly shifts the $\alpha$ relaxation to higher temperatures. These effects indicate that the exfoliated graphite may have a reinforcing effect on the PP matrix. Also, this increase in the loss moduli ( $T_{g}$ modified) in the nanocomposites could suggest certain influence in the impact strength.

The complex viscosity of PP/EG nanocomposites with different amounts of nanofiller is shown in Figure 5. The complex viscosity is used to predict the viscoelastic behavior of materials under oscillatory shear forces during extrusion, blow molding, compression molding and other industrial processes ${ }^{[20]}$. A Newtonian plateau, which characterizes liquid-like relaxation, was observed at low
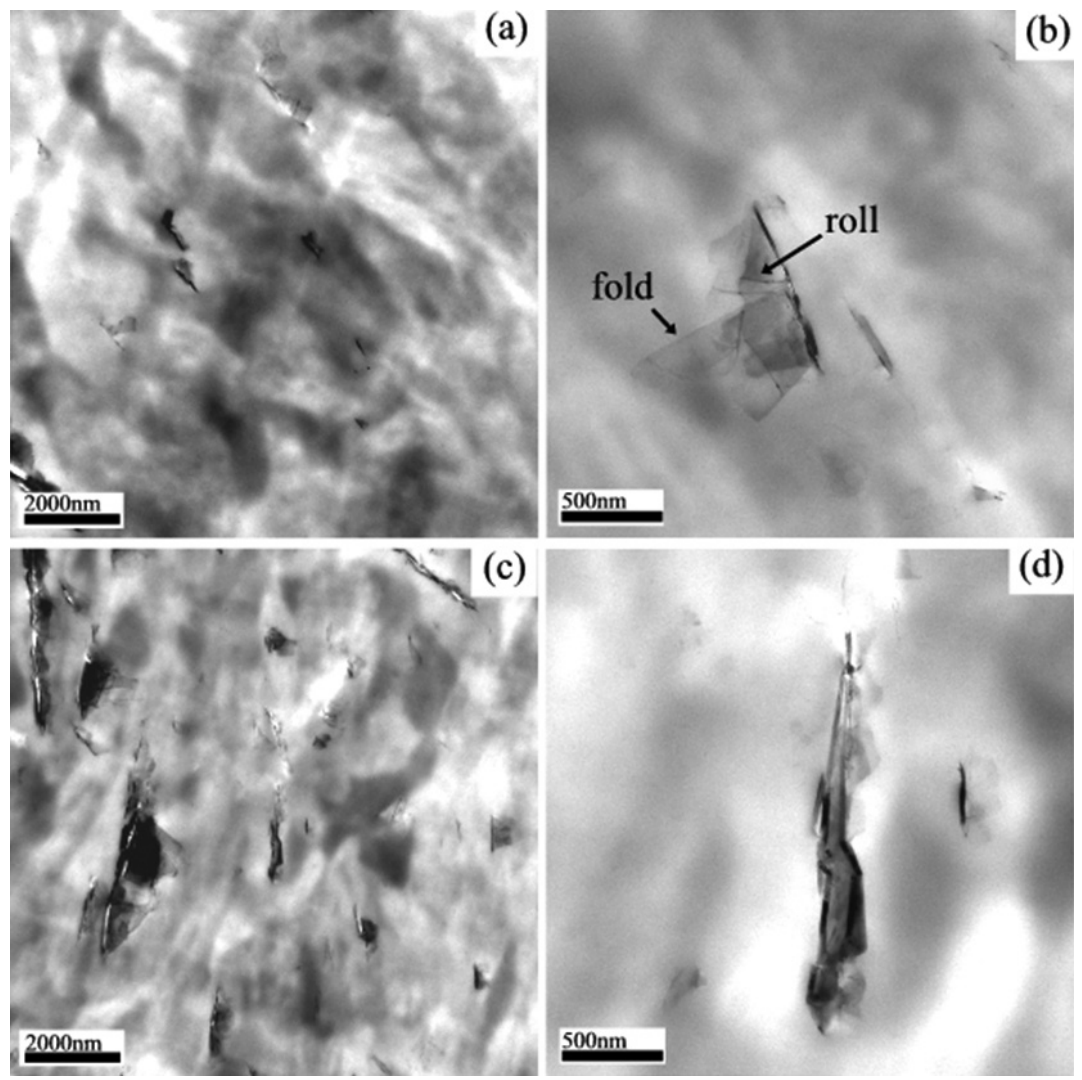

Figure 2. TEM micrographs of (a)-(b) PP/EG-2 and (c)-(d) PP/EG-10 nanocomposites.

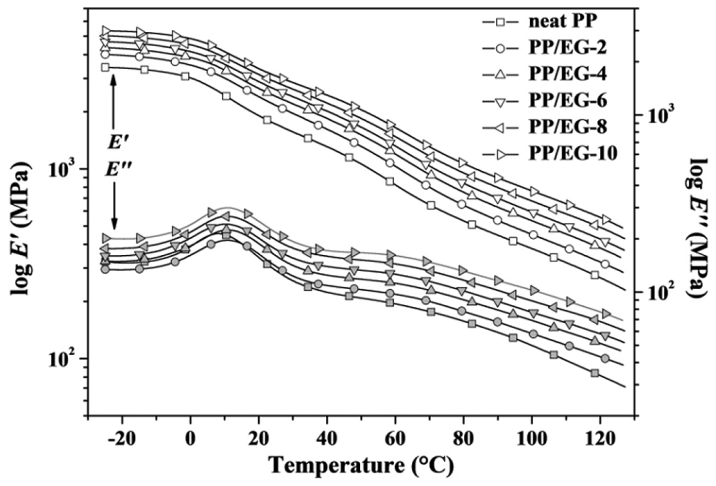

Figure 3. Storage $\left(E^{\prime}\right)$ and loss $\left(E^{\prime \prime}\right)$ moduli as functions of temperature for the PP/EG nanocomposites.

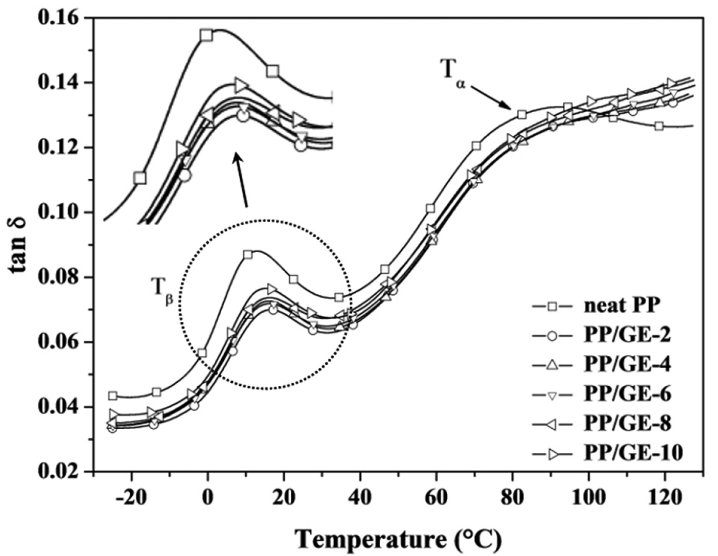

Figure 4. Loss factor $(\tan \delta$ ) for the PP/EG nanocomposites. 


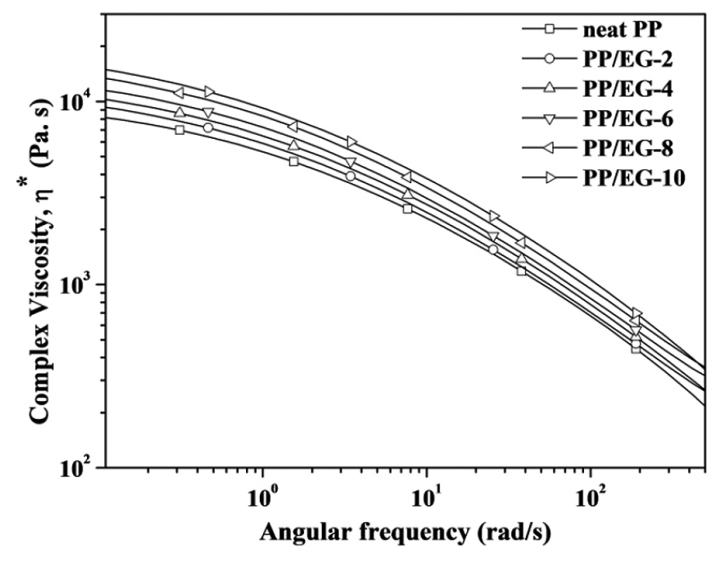

Figure 5. Complex viscosity as a function of angular frequency $(\omega)$ for the PP/EG nanocomposites.

frequencies for every sample. Pseudoplastic behavior at frequencies above $10^{\circ} \mathrm{rad} / \mathrm{s}$ and decreasing complex viscosity at higher frequencies were observed for all samples. These behaviors are due to the hydrodynamic effect of the nanofiller in the melted polymer; similar effects are observed in conventional composites ${ }^{[21-23]}$.

In this work, the PP chains are expected to relax fully and exhibit terminal behavior similar to linear polymers with scaling relations of approximately $G^{\prime}-\omega^{2}$ and $G^{\prime \prime}-\omega^{1}$ at low frequencies at the experimental temperature ${ }^{[24]}$. In the low frequency range, the frequency dependent behavior of PP was G'- $\omega^{1.29}$ and G" $-\omega^{0.85}$, which may be due to the broad molecular weight distribution of $\mathrm{PP}^{[25]}$. The scaling laws for the angular frequency dependence of $G$ ' and $G$ "' of the nanocomposites are shown in Table 1 .

In most nanocomposites, the slopes of $G$ ' and $G$ " decrease gradually with an increase of the level of nanofiller and approach a plateau ("non-terminal behavior") that tends toward pseudo-solid rheological behavior $^{[26,27]}$. Non-terminal behavior usually occurs in intercalated and exfoliated nanocomposites, where the individual lamellae or tactoids hinder the free rotation and relaxation of the polymer chains. The extent of the effects of nanoparticles on polymer relaxation depends on the nanocomposite microstructure and the nanofiller/matrix affinity. In nanocomposites where there are no significant interactions between the components (matrix and nanofiller), the graphs of $G^{\prime}, G^{\prime \prime}$ and viscosity increase with the angular frequency, and the curves resemble those for the neat polymer because the nanofiller does not modify the angular frequency dependence ${ }^{[28]}$. This behavior was observed for the PP/EG nanocomposites (Figure 6), where the profiles of the $G$ ' and $G$ ' curves resembled those for polypropylene. In addition, the TEM images and viscosity data suggested that the interactions between the graphite and polymer were not significant.

As discussed above, the rheological properties of PP/exfoliated graphite nanocomposites provided important information about the interactions between the components in the system. The behavior of the nanocomposites was similar to the behavior of polypropylene. The absence of non-terminal behavior
Table 1. Slopes of $G$ ' and G" versus angular frequency $(\omega)$ for the PP/EG nanocomposites.

\begin{tabular}{ccc}
\hline Samples & Slope of $\boldsymbol{G}$ ' $\boldsymbol{v s}$. & Slope of $\boldsymbol{G}$ ' $\boldsymbol{v} \boldsymbol{s . \omega}$ \\
\hline neat PP & 1.29 & 0.85 \\
PP/EG-2 & 1.22 & 0.83 \\
PP/EG-4 & 1.21 & 0.83 \\
PP/EG-6 & 1.19 & 0.83 \\
PP/EG-8 & 1.15 & 0.82 \\
PP/EG-10 & 1.11 & 0.81 \\
\hline
\end{tabular}

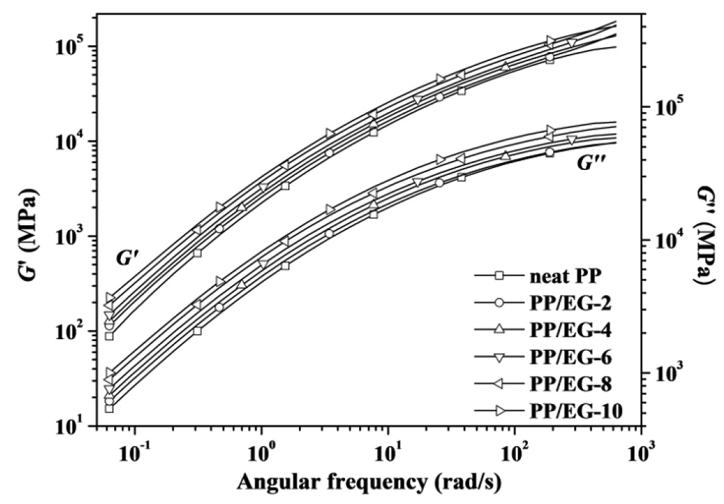

Figure 6. Storage $\left(G^{\prime}\right)$ and loss $\left(G^{\prime \prime}\right)$ moduli as a function of angular frequency $(\omega)$ for the PP/EG nanocomposites.

for nanocomposites implied that the polymer-nanofiller interactions were weak. The graphite could act as a reinforcing agent in the polymer matrix, did not modify the polymer relaxation and increased the modulus of the nanocomposite material.

\section{Mechanical properties of PP/EG nanocomposites}

The flexural moduli of the nanocomposites are presented in Table 2. The incorporation of exfoliated graphite nanoparticles significantly enhanced the Young's modulus (up to 75\%). The reinforcing effect of EG, which was observed in the solid viscoelastic measurements, was also detected in the three-point flexural tests. Torkelson ${ }^{[29]}$ observed that the addition of up to $2.5 \mathrm{wt} \%$ graphite to neat PP (using a solid-state shear pulverization (SSSP) technique) can increase the yield strength by approximately $60 \%$ and increase Young's modulus by $100 \%$ relative to neat PP. The authors attributed these enhancements to the homogeneous dispersion of graphene nanosheets and the effective load transfer from the matrix to graphene. The increase in the flexural modulus was related to the transfer of stress when graphene particles formed small clusters. The same effect could have occurred in the nanocomposites in this study, where the particles were well distributed in the TEM images and the stress load was transferred effectively as the modulus increased.

The tensile strength was not reduced in the nanocomposites with exfoliated graphite and had an increase compared to PP (up to $18 \%$ - Table 2). This property can be used to assess the efficiency of dispersion of the nanofiller since in agglomerated systems the stress 
Table 2. Mechanical properties of the PP/EG nanocomposites.

\begin{tabular}{cccc}
\hline Samples & Flexural Modulus $(\mathbf{G P a})$ & Impact Izod at $\mathbf{2 3}{ }^{\circ} \mathbf{C}(\mathbf{J} / \mathbf{~ m})$ & Tensile Strenght $(\mathbf{M P a})$ \\
\hline neat PP & $1.42 \pm 0.02$ & $34 \pm 2$ & $32 \pm 0.4$ \\
PP/EG-2 & $1.85 \pm 0.05$ & $33 \pm 2$ & $36 \pm 0.1$ \\
PP/EG-4 & $2.04 \pm 0.03$ & $32 \pm 1$ & $34 \pm 0.4$ \\
PP/EG-6 & $2.18 \pm 0.05$ & $32 \pm 3$ & $37 \pm 0.2$ \\
PP/EG-8 & $2.41 \pm 0.03$ & $30 \pm 4$ & $37 \pm 0.3$ \\
PP/EG-10 & $2.49 \pm 0.05$ & $29 \pm 3$ & $38 \pm 0.2$ \\
\hline
\end{tabular}
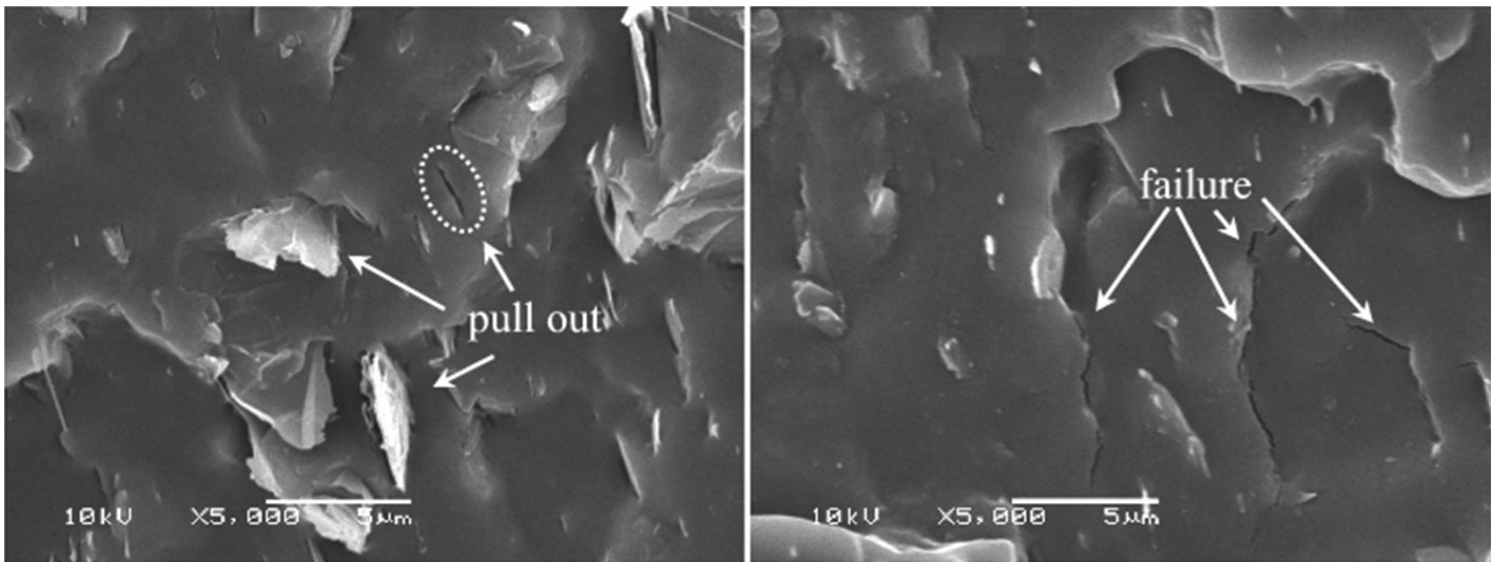

Figure 7. SEM micrographs of the fractured PP/EG-2 nanocomposites.

transmission to the matrix is hindered and the strength of the material decreases ${ }^{[30]}$.

The Izod impact strength did not change significantly with the exfoliated graphite content, although there was a slight tendency for the impact strength to decrease (Table 2). Conventional fillers can decrease the impact strength due to the formation of tensional points that can act as a matrix failure points ${ }^{[31]}$. In nanocomposites, nanofillers can increase the plastic deformation of the matrix in the interfacial region, the failure deviation, and the cracks and microvoids formed at the interface. These mechanisms could enhance the energy absorption and the impact strength in the nanocomposites. When there are weak interactions between PP and EG, voids and cracks may appear at the interface and create a failure switch mechanism, which increases energy dissipation and crack resistance in the nanocomposites ${ }^{[32,33]}$. Even with the addition of a nanofiller that is more resistant to stress than the matrix, there is no significant loss in impact strength, as generally occurs in nanocomposites ${ }^{[8]}$.

The fracture mechanism in PP/EG nanocomposites is illustrated in Figure 6. These SEM micrographs show samples after they fractured during Izod impact testing. When the samples fractured, the graphene layers pulled out and left spaces in the matrix (Figure 7). The weak strength of the interfacial adhesion (discussed above) generates this type of failure. The crack dissipation over the interfaces (Figure 7) is another indication of the weak interactions between the nanofiller and the matrix.

As pointed by several authors ${ }^{[34,35]}$, the mechanical properties of the nanocomposites depend on the nanofiller content, the interfacial interaction between the components of the material, and the distribution and alignment in the matrix. Previous studies ${ }^{[36]}$ showed that exfoliated graphite can act as a nucleating agent to the crystallization of polypropylene and this effect only occur if the affinity between both exists. Eitan et al. ${ }^{[37]}$ observed the mechanism for improving the mechanical properties of the MWCNT/polycarbonate nanocomposites corresponds to the immobilization of the polymer chains at the surface of the nanofiller, and this effect is pronounced when the good dispersion is achieved. Also, the main factor to improve the mechanical properties in the studied systems is the good dispersion of the nanofiller in the matrix due to the efficiency in the processing process. In our case, the interaction between the exfoliated graphite and the polypropylene was found to be weak once the graphene layers appear folded and rolled but not crumpled.

\section{Conclusions}

The nanofillers were homogeneously dispersed in the matrix; TEM analysis revealed the presence of small agglomerates and a few graphene layers separated from the tactoids. Exfoliated graphite did not interact significantly with the matrix, as observed through TEM images of interfacial detachment and the results for G', G" moduli and viscosity, where the behavior of nanocomposites was similar to that of the polypropylene. The graphite acted as a reinforcing agent in the polymer matrix. In addition, the mechanical properties of the nanocomposites improved significantly in terms of their flexural and storage moduli, and there was little loss of 
impact strength, which suggests that graphite can be used as nanofiller for nanocomposites.

\section{Acknowledgements}

The authors are grateful to Braskem S/A, FINEP, CNPq and FAPERGS/ PRONEX for financial support.

\section{References}

1. Potts, J. R.; Dreyer, D. R.; Bielawski, C. W. \& Ruoff, R. S. - Polymer, 52, p.5 (2011). http://dx.doi.org/10.1016/j. polymer.2010.11.042

2. Kim, H.; Abdala, A. A. \& Macosko, C. W. - Macromolecules, 43, p.6515 (2010). http://dx.doi. org/10.1021/ma100572e

3. Kim, H. \& Macosko, C. W. - Macromolecules, 41, p.3317 (2008). http://dx.doi.org/10.1021/ma702385h

4. Ferreira, C. I.; Oviedo, M. A. - Nanocompósitos de grafite dispersos em matrizes poliméricas e processo de obtenção desses, M.R. S., Brazil Patent, 1104143-9 (2011).

5. Thostenson, E.T.; Li, C.; Chou, T.-W.- Compos. Sci. Technol., 65, (2005).

6. Viculis, L. M.; Mack, J. J.; Mayer, O. M.; Hahn, H. T.; Kaner, R. B. - J. Mater. Chem., 15, p.974 (2005). http:// dx.doi.org/10.1039/b413029d

7. Hummers, W. S. \& Offeman, R. E. - J. Am. Chem. Soc., 80, p.1339 (1958). http://dx.doi.org/10.1021/ja01539a017

8. Kalaitzidou, K.; Fukushima, H. \& Drzal, L. T. - Compos. Part A, Appl. Sci. Manuf., 38, p.1675 (2007). http://dx.doi. org/10.1016/j.compositesa.2007.02.003

9. Kalaitzidou, K.; Fukushima, H. \& Drzal, L.T. - Compos. Sci. Technol., 67, p.2045 (2007). http://dx.doi.org/10.1016/j. compscitech.2006.11.014

10. Dal Castel, C.; Bianchi, O.; Oviedo, M. A. S.; Liberman, S. A.; Mauler, R. S. \& Oliveira R. V. B. - Mater. Sci. Eng., C, 29, p.602 (2009). http://dx.doi.org/10.1016/j. msec.2008.10.012

11. Zhao, J.; Morgan, A. B. \& Harris, J. D. - Polymer, 46, p.8641 (2005). http://dx.doi.org/10.1016/j.polymer.2005.04.038

12. Jäger, K.-M. \& Eggen, S.S. - Polymer, 45, p.7641 (2004). http://dx.doi.org/10.1016/j.polymer.2004.08.073

13. Leonardi, F.; Derail, C. \& Marin, G. - J. Non-Newtonian Fluid Mech., 128, p.50 (2005). http://dx.doi.org/10.1016/j. jnnfm.2005.03.012

14. Nakajima, T. \& Matsuo, Y. - Carbon, 32, p.469 (1994) http://dx.doi.org/10.1016/0008-6223(94)90168-6

15. McAllister, M. J.; Li, J.-L.; Adamson, D. H.; Schniepp, H. C.; Abdala, A. A.; Liu, J.; Herrera-Alonso, M.; Milius, D. L.; Car, R.; Prud'homme, R. K. \& Aksay, I. A. - Chem. Mater., 19, p.4396 (2007). http://dx.doi.org/10.1021/ $\mathrm{cm} 0630800$

16. Kim, H.; Miura, Y. \& Macosko, C. W. - Chem. Mater., 22, p.3441 (2010). http://dx.doi.org/10.1021/cm100477v
17. Hirata, M.; Gotou, T.; Horiuchi, S.; Fujiwara, M. \& Ohba, M. - Carbon, 42, p.2929 (2004). http://dx.doi.org/10.1016/j. carbon.2004.07.003

18. Yamaguchi, M.; Miyata, H. \& Nitta, K. H. - J. Appl. Polym. Sci., 62, p.87 (1996). http://dx.doi.org/10.1002/(SICI)10974628(19961003)62:1<87::AID-APP12>3.0.CO;2-5

19. Lim, J. W.; Hassan, A.; Rahmat, A.R. \& Wahit, M.U. - Polym. Int., 55, p.204 (2006).

20. Lertwilmolnun, W. \& Vergnes, B. - Polymer, 46, p.3462 (2005). http://dx.doi.org/10.1016/j.polymer.2005.02.018

21. Treece, M. A. \& Oberhauser, J. P.- Polymer, 48, p.1083 (2007). http://dx.doi.org/10.1016/j.polymer.2006.12.029

22. Filippone, G.; Dintcheva, N. T.; Acierno, D. \& La Mantia, F. P. - Polymer, 49, p.1312 (2008). http://dx.doi.org/10.1016/j. polymer.2008.01.045

23. Wang, Y.; Xu, J.; Bechtel, S. \& Koelling, K. - Rheol. Acta, 45, p.919 (2006). http://dx.doi.org/10.1007/s00397005-0077-8

24. Zhou, Z.; Zhang, Y.; Zhang, Y. \& Yin, N. - J. Polym. Sci. Part B: Polym. Phis., 46, p.526 (2008). http://dx.doi. org/10.1002/polb.21386

25. Krishnamoorti, R. \& Giannelis, E. P. - Macromolecules, 30, p.4097 (1997). http://dx.doi.org/10.1021/ma960550a

26. Lim, Y. T. \& Park, O. O. - Rheol. Acta, 40, (2001).

27. Galgali,G.; Ramesh, C. \& Lele, A. - Macromolecules, 34, p.852 (2001). http://dx.doi.org/10.1021/ma000565f

28. Krishnamoorti, R.; Vaia, R. A. \& Giannelis, E. P. - Chem. Mater., 8, p.1728 (1996). http://dx.doi.org/10.1021/ cm960127g

29. Wakabayashi, K.; Brunner, P. J.; Masuda, J. I.; Hewlett, S. A. \& Torkelson, J. M. - Polymer, 51, p.5525 (2010). http:// dx.doi.org/10.1016/j.polymer.2010.09.007

30. Nielsen, L. E. ed. - "Mechanical Properties of Polymers and Composites", Marcel Dekker, New York (1994).

31. Fu, S.-Y.; Feng, X.-Q.; Lauke, B. \& Mai, Y.W. - Compososites Part B: Engineering, 39, p.933 (2008). http://dx.doi.org/10.1016/j.compositesb.2008.01.002

32. Lin, Y.; Chen, H. \& Chan, C.-M. J. Wu - Macromolecules, 41, p.9204 (2008).

33. Yuan, Q. \& Misra, R. D. K. - Polymer, 47, p.4421 (2006). http://dx.doi.org/10.1016/j.polymer.2006.03.105

34. Alexandre, M. \& Dubois, P. - Mater. Sci. Eng., 28, p.1 (2000). http://dx.doi.org/10.1016/S0927-796X(00)00012-7

35. Fornes, T. D. \& Paul D. R. - Polymer, 44, p.4993 (2003). http://dx.doi.org/10.1016/S0032-3861(03)00471-3

36. Ferreira, C. I.; Dal Castel, C.; Oviedo, M. A. S. \& Mauler, R. S. - Thermochim. Acta, 553, p.40 (2013). http://dx.doi. org/10.1016/j.tca.2012.11.025

37. Eitan, A.; Fisher, F. T.; Andrews, R.; Brinson, L. C. \& Schadler, L. S. - Comp. Sci.Technol., 66, p.1162 (2006). http://dx.doi.org/10.1016/j.compscitech.2005.10.004

Received: 07/30/12

Revised: $12 / 26 / 12$

Accepted: 01/21/13 